\title{
Subtribo Myrciinae O. Berg (Myrtaceae) na Restinga da Marambaia, RJ, Brasil ${ }^{1}$
}

\author{
Marcelo da Costa Souza ${ }^{2,5}$, Marli Pires Morim² ${ }^{2}$, Marilena de Menezes Silva Conde e $^{3}$ \\ Luis Fernando Tavares de Menezes ${ }^{4}$
}

Recebido em 31/10/2005. Aceito em 3/08/2006

\begin{abstract}
RESUMO - (Subtribo Myrciinae O. Berg (Myrtaceae) na Restinga da Marambaia, RJ, Brasil). A família Myrtaceae é uma das famílias com maior riqueza de espécies nas Restingas. O principal objetivo deste trabalho foi o levantamento da subtribo Myrciinae (Myrtaceae)

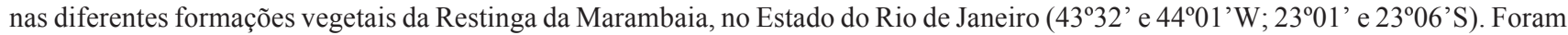
registradas as ocorrências dos seguintes táxons: Calyptranthes brasiliensis Spreng., Gomidesia fenzliana O. Berg, G. martiana O. Berg, Marlierea tomentosa Cambess., Myrcia acuminatissima O. Berg, M. lundiana Kiaersk., M. multiflora (Lam.) DC., M. recurvata O. Berg e M. richardiana (O. Berg) Kiaersk. Dois novos sinônimos são propostos para esta última espécie: Aulomyrcia lúcida O.Berg e Myrcia grandiglandulosa Kiaersk. Apresenta-se uma chave de identificação para as espécies, bem como descrições, ilustrações, dados relativos às épocas de floração e frutificação e distribuição geográfica.
\end{abstract}

Palavras-chaves: Myrciinae, Myrtaceae, florística, taxonomia, Restinga da Marambaia

\begin{abstract}
Subtribe Myrciinae O. Berg (Myrtaceae) at Marambaia Restinga, Rio de Janeiro State, Brazil). The family Myrtaceae is one of the most species-rich families in restinga vegetation. The main objective of this paper was to survey the subtribe Myrciinae (Myrtaceae) in the different vegetation types of Marambaia Restinga, Rio de Janeiro, Brazil $\left(43^{\circ} 32^{\prime}-44^{\circ} 01^{\prime} \mathrm{W} ; 23^{\circ} 01^{\prime}-23^{\circ} 06^{\prime} \mathrm{S}\right)$. The following taxa were found: Calyptranthes brasiliensis Spreng., Gomidesia fenzliana O.Berg, G. martiana O. Berg, Marlierea tomentosa Cambess., Myrcia acuminatissima O. Berg, M. lundiana Kiaersk., M. multiflora (Lam.) DC., M. recurvata O. Berg, and M. richardiana (O. Berg) Kiaersk. Two new synonyms are proposed for the last specie: Aulomyrcia lucida O. Berg and Myrcia grandiglandulosa Kiaersk. A species key is given, as well as descriptions, illustrations, data on flowering and fruiting periods, and geographic distributions of the species.
\end{abstract}

Key words: Myrciinae, Myrtaceae, floristics, taxonomy, Marambaia Restinga

\section{Introdução}

As Myrtaceae brasileiras pertencem à tribo Myrteae, formando um grupo filogeneticamente coeso (Wilson et al. 2001). Candolle (1826), com base na estrutura dos embriões, dividiu a tribo Myrteae em três grupos. Berg $(1855 ; 1856 \mathrm{a} ; 1856 \mathrm{~b} ; 1857 ; 1858 ; 1859)$ considerou os três grupos de Candolle como subtribos: Myrciinae O. Berg, Myrtinae O. Berg e Eugeniinae O. Berg.

A subtribo Myrciinae se caracteriza por apresentar embrião do tipo mircióide, ou invaginado plicado segundo Barroso et al. (1999), com eixo hipocótiloradícula e cotilédones distintos entre si, não contínuos, amplos, maiores que o eixo, foliáceos, dobrados e plicados em torno do eixo hipocótilo-radícula. Atualmente são reconhecidos quatro gêneros subordinados à subtribo Myrciinae: Calyptranthes Sw., Gomidesia O. Berg, Marlierea Cambess. e Myrcia DC. ex Guill. (Lucas et al. 2005). Os referidos táxons têm distribuição restrita ao Neotrópico (Lucas et al. 2005).

A família é uma das mais importantes em comunidades neotropicais (Mori et al. 1983) e tem sido freqüentemente citada em estudos florísticos e/ou fitossociológicos realizados nas restingas do Estado do Rio de Janeiro como a de maior riqueza de espécies (Araujo 2000; Assumpção \& Nascimento 2000; Pereira et al. 2001). Destaca-se, entretanto, a ausência de estudos floristico-taxonômicos detalhados para o grupo

\footnotetext{
1 Parte da dissertação de Mestrado do primeiro Autor, Programa de Pós-Graduação em Botânica da Escola Nacional de Botânica Tropical, Instituto de Pesquisas Jardim Botânico do Rio de Janeiro

2 Instituto de Pesquisas Jardim Botânico do Rio de Janeiro, Rua Pacheco Leão 915, Jardim Botânico, 22460-030 Rio de Janeiro, RJ, Brasil

3 Universidade Federal Rural do Rio de Janeiro, Instituto de Biologia, Departamento de Botânica

4 Universidade Federal do Espírito Santo, Centro Universitário Norte do Espírito Santo, Departamento de Ciências da Saúde, Biológicas e Agrárias

5 Autor para correspondência: msouza@jbrj.gov.br
} 
e o número de espécies atualmente conhecido, para as restingas do Rio de Janeiro, é subestimado, considerando-se o grande número de espécimes indeterminados nos herbários (Araujo 2000).

O presente trabalho tem como objetivo realizar o tratamento taxonômico da subtribo Myrciinae, nas diversas formações vegetais da Restinga da Marambaia, bem como informar sobre a distribuição geográfica expandida das espécies.

Material e métodos

A Restinga da Marambaia localiza-se no Estado do Rio de Janeiro, compreendida pelos municípios do Rio de Janeiro, Itaguaí e Mangaratiba, entre os meridianos $43^{\circ} 32^{\prime}$ e $44^{\circ} 01^{\prime} \mathrm{W}$ e os paralelos $23^{\circ} 01^{\prime}$ e $23^{\circ} 06^{\prime} \mathrm{S}$. É formada por uma longa faixa de areia, que separa a Baía de Sepetiba do Oceano Atlântico, abrangendo uma área de aproximadamente 4.940 ha e uma extensão de cerca de $40 \mathrm{~km}$ (Fig. 1). Menezes \& Araujo (2005) reconhecem 11 formações vegetais na Restinga da Marambaia: quatro formações herbáceas (herbácea aberta de praia, herbácea fechada inundável, herbácea fechada inundada e herbácea fechada de cordão arenoso), quatro formações arbustivas (arbustiva aberta não inundável, arbustiva aberta inundável, arbustiva fechada de cordão arenoso e arbustiva fechada de pós-praia) e três formações florestais (floresta inundada, floresta inundável e floresta de cordão arenoso).

O trabalho de campo abrangeu o período de 2000 a 2004, priorizando-se as épocas de floração e frutificação dos indivíduos. Foram percorridas as onze formações vegetais para constatação de ocorrência das espécies. O material foi coletado e herborizado segundo os procedimentos citados em Vaz et al. (1992) e depositado no herbário do Departamento de Botânica da Universidade Federal Rural do Rio de Janeiro (RBR) com duplicatas no herbário do Instituto de Pesquisas Jardim Botânico do Rio de Janeiro (RB).

As coleções dos herbários RBR, RB, R, GUA foram consultadas a fim de verificar a distribuição geográfica e épocas de floração e frutificação das espécies, além de complementar informações não obtidas nos materiais da área de estudo. As siglas dos herbários visitados estão de acordo com Holmgren et al. (1990).

Os dados dendrológicos foram descritos de acordo com Ribeiro et al. (1999) e Marchiori (1995). Para as descrições de indumento utilizaram-se as definições de Harrington \& Durrel (1957). A terminologia utilizada para a arquitetura foliar segue Hickey (1973). As inflorescências foram descritas segundo os conceitos de Briggs \& Johnson (1979). Os tipos de frutos e de embriões foram reconhecidos com base na classificação de Barroso et al. (1999).

\section{Resultados e discussão}

\section{Subtribo Myrciinae}

Inflorescências axilares terminais, axilares em nós folhosos ou em outras regiões dos ramos na axila de ferofilos, em tirsóides ou panículas; flores pentâmeras; botão floral de cálice aberto ou fechado, abrindo-se pelo rasgamento do hipanto em 4-5 lobos irregulares ou por uma caliptra; pétalas presentes, reduzidas ou ausentes; androceu polistêmone, com abertura da antera rimosa reta ou sigmóide; hipanto elevado acima do ovário ou não; ovário bi ou trilocular, biovular por

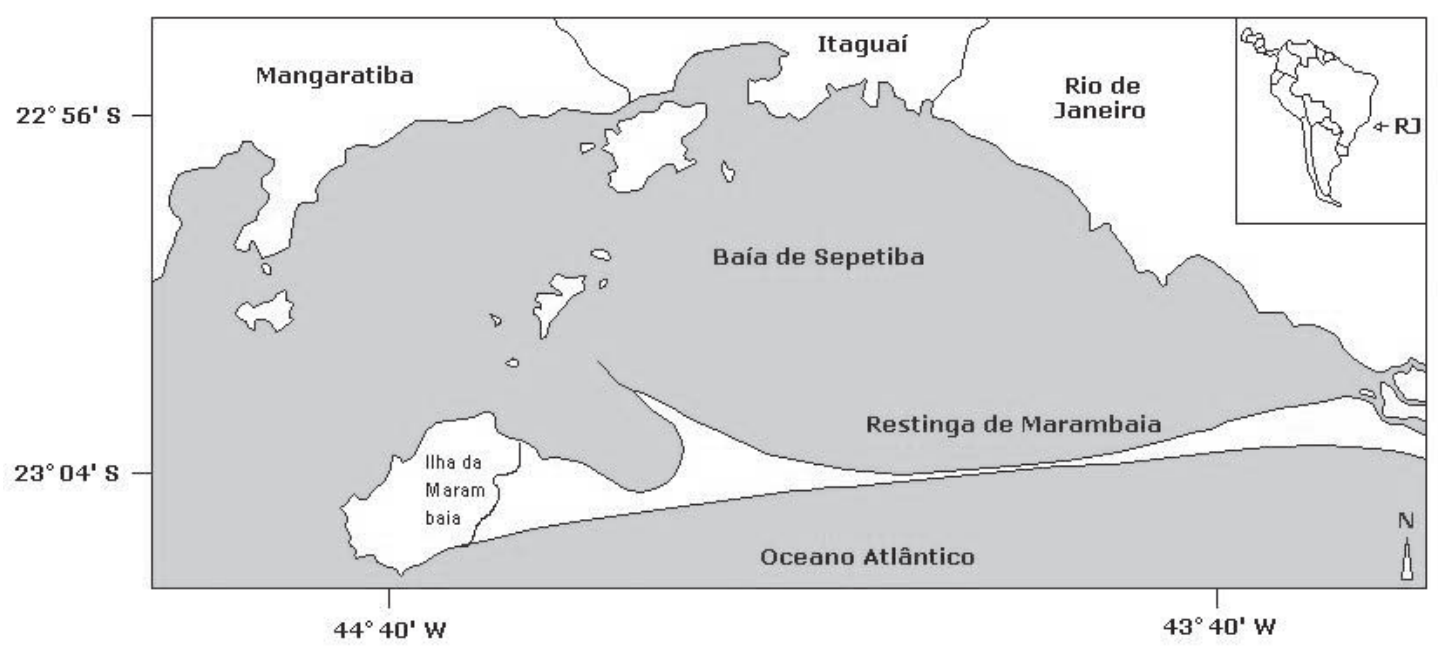

Figura 1. Localização da Restinga da Marambaia, RJ, Brasil. 
lóculo. Fruto bacóide, do sub-tipo bacáceo, com 1-2 sementes; embrião mircióide, com cotilédones livres, amplos, foliáceos, dobrados, circundados pelo eixo hipocótilo-radícula, longo.

A subtribo Myrciinae está representada na Restinga da Marambaia por nove espécies, distribuídas entre os gêneros: Calyptranthes,
Marlierea, Gomidesia e Myrcia, sendo Myrcia o de maior riqueza de espécies (5). As espécies ocorrem em seis formações vegetais das onze descritas para a Restinga da Marambaia. A formação denominada floresta de cordão arenoso destaca-se por abranger o maior número de espécies da subtribo Myrciinae (8).

Chave de identificação para as espécies da Subtribo Myrciinae (Myrtaceae) da Restinga da Marambaia

1. Botão floral com cálice fechado, lobos caliciniais não distintos

2. Cálice abrindo-se por uma caliptra; ramos, pecíolos e face abaxial das folhas, quando novos, inflorescências, flores e frutos ferrugíneo-pubescente 1.1. Calyptranthes brasiliensis

2. Cálice abrindo-se em lobos (4-5), irregulares, profundamente fendidos; ramos e folhas novos, inflorescências, flores e frutos albo-tomentosos 3.1. Marlierea tomentosa

1. Botão floral com cálice aberto, com 5 lobos caliciniais distintos

3. Anteras com abertura sigmóide

4. Ramos novos, ambas as faces das folhas novas, inflorescências, flores e frutos com indumento amarelado-pardacento, viloso; folhas obovadas ou elípticas, com ápice obtuso, arredondado ou retuso; ovário trilocular

2.1. Gomidesia fenzliana

4. Ramos novos, somente a face abaxial das folhas, inflorescências, flores e frutos com indumento amarelo, farináceo; folhas lanceoladas ou oblongas, com ápice acuminado; ovário bilocular .... 2.2. Gomidesia martiana

3. Antera com abertura reta

5. Hipanto não prolongado acima do ápice do ovário

4.4. Myrcia recurvata

5. Hipanto prolongado acima do ápice do ovário

6. Inflorescência do tipo tirsóide; ovário trilocular

6. Inflorescência do tipo panícula; ovário bilocular

7. Botão floral com globo petalífero aparente até cerca da metade do tamanho do botão; cálice com lobos pouco salientes 4.3. Myrcia multiflora

7. Botão floral com globo petalífero pouco ou não aparente no ápice do botão; cálice com lobos proeminentes

8. Ramos jovens, inflorescências, flores e frutos jovens canescentes e vilosos; folhas canescente pubescente

8. Ramos, folhas e frutos glabros; ramos da inflorescência avermelhados e tomentosos; flores, quando em botão, pubescentes no ápice 4.2. Myrcia lundiana

1. Calyptranthes Sw., Prodr. 5: 79. 1788.

Lectótipo: C. chytraculia (L.) Sw., designado por McVaugh (1968).

Gênero distribuído desde o México e Caribe até norte da Argentina, com provavelmente mais de 100 espécies, sendo que a maioria delas ocorre no sudeste do Brasil (McVaugh 1968; Landrum \& Kawasaki 1997).

1.1. Calyptranthes brasiliensis Spreng., Syst. Veg., editio decima sexta 2: 499. 1825.

Tipo: Brasilia, Sellow s.n., s.d. (foto do isótipo P!).

Fig. 2-7
Arbusto a árvore de até 8 metros de altura, ramos, pecíolos, face abaxial das folhas, inflorescências, flores e frutos, quando novos, com indumento ferrugíneopubescente, tricomas dibraquiados de até $1 \mathrm{~mm}$ compr.; ramos velhos glabros e esfoliando em placas, porções terminais dos ramos com ramificações dicotômicas; tronco com casca externa laminada desfoliante em placas rígidas, deixando um aspecto liso e avermelhado. Folhas elíptica-oblongas ou ovadas, ápice levemente obtuso-acuminado ou agudo, base aguda ou obtusa, bordo um pouco revoluto, coriáceas, discolores, com pontuações evidentes em ambas as faces, 50-125 $\times 25-50 \mathrm{~mm}$; nervura principal sulcada na face 

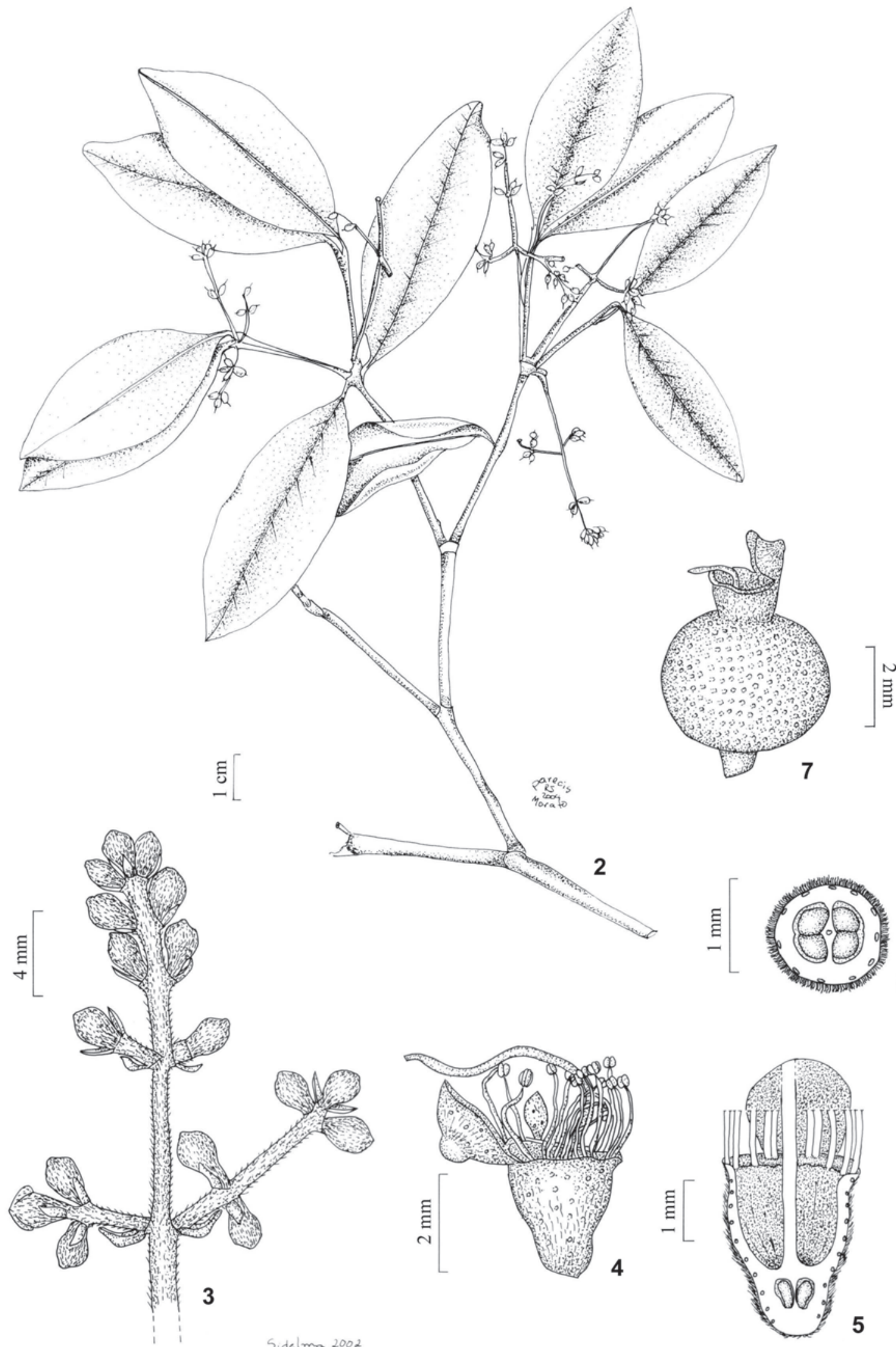

Figuras 2-7. Calyptranthes brasiliensis Spreng: 2. Hábito. 3. Inflorescência (Souza 168). 4. Flor após antese. 5. Corte longitudinal da flor. 6. Corte transversal do ovário (Menezes 698). 7. Fruto (Menezes s.n.). 
adaxial e saliente na abaxial; nervuras secundárias 12-17 pares, às vezes visíveis na face adaxial, visíveis e um pouco salientes na abaxial; nervura marginal 1,5-2 $\mathrm{mm}$ do bordo; nervura intramarginal ca. 0,3-0,5 $\mathrm{mm}$ do bordo; pecíolo com 5-8 $\mathrm{mm}$ compr., enegrecido depois de herborizado. Inflorescências em tirsóides, 4 ramifloras, 40-110 mm compr., hipopódio de 25-50 mm compr.; 2-3 pares de ramificações laterais, opostos, ramificados ou não, terminados por 3, 7 ou mais flores aglomeradas; ferofilos ovados, 3-5 mm compr., decíduos; profilos ovados, com ca. $2 \mathrm{~mm}$ compr., decíduos; botões florais obovados com ápice acuminado, 2-3 mm compr.; botão floral com cálice fechado, abrindo-se por uma caliptra; pétalas 3 , pequenas, caducas; hipanto desenvolvido sobre o ápice do ovário; ovário bilocular. Fruto bacáceo globoso, ca. $5 \mathrm{~mm}$ diâm., negro quando maduro, coroado pelo cálice e por vezes com caliptra persistente; sementes 1-2 por fruto.

Distribuição geográfica: da Bahia a Santa Catarina, ocorrendo na Floresta Pluvial Atlântica em ambientes com solos úmidos que se transformam em brejos temporários (Legrand \& Klein 1971b), na Mata de Tabuleiro do Espírito Santo (Barroso \& Peixoto 1995) e nas Restingas. No Rio de Janeiro ocorre nas seguintes áreas de restinga: Restinga da Marambaia, Jacarepaguá, Maricá, Cabo Frio, Macaé e São João da Barra. Na Restinga da Marambaia foi encontrada na formação arbustiva aberta não inundável, arbustiva aberta inundável, floresta inundável e floresta de cordão arenoso.

Floração: de novembro a abril. Frutificação: de março a julho.

Comentários: a espécie apresenta as porções terminais dos ramos com uma ramificação dicotômica, além de indumento com tricomas dibraquiados, caracteres estes muito comuns ao gênero, e indumento com coloração ferrugínea.

Nomea comuns: guamirim-branco, batinga-mirim.

Material examinado: BRASIL. Rio de Janeiro: Mangaratiba, Restinga da Marambaia, 22/XII/1998, fl., Menezes 232 (RBR); 23/XII/1998, fl., Menezes s.n. (RBR); 29/V/1999, fr., Menezes s.n. (RBR); 8/IV/2000, fl., Menezes 698 (RBR); 19/I/2001, fl., Souza 164 (RBR); 20/I/2001, fl., Souza 168 (RBR); 22/II/2003, fl., Menezes 1060 (RBR); 13/III/2003, fr., Menezes s.n. (RBR).

2. Gomidesia O. Berg, Linnaea 27: 6. 1855-56. Lectótipo: G. spectabilis (DC.) O. Berg, designado por McVaugh (1956).
Landrum \& Kawasaki (1997) mencionaram uma possível união deste gênero com Myrcia, uma vez que as diferenças que os separam são tênues. Apenas a morfologia das anteras, no tocante a deiscência rimosa sigmóide, distingue Gomidesia de Myrcia. No presente trabalho ambos os gêneros são mantidos distintos até que estudos mais detalhados definam a relação entre eles.

As espécies de Gomidesia são quase que exclusivas do sul e sudeste do Brasil, com limite austral no Paraguai, nordeste da Argentina e norte do Uruguai; poucas espécies chegam até o norte da Bahia, entretanto podem ocorrer nas Antilhas (McVaugh 1968).

2.1. Gomidesia fenzliana O. Berg, Fl. bras. 14(1): 20, pl. I, 8. 1857.

Tipo: Habitat in prov. Minas Gerais: Claussen, coll. n.2100.; et in arenosis turfosis prope Rio de Janeiro: Sellow, Mart., hb. Fl. Bras. n. 683 (foto do isosintipo K!), Schott, coll. n.1078 (foto do isosintipo $\mathrm{K}$ !), Luschnath (foto do isosintipo OXF!).

Fig. 8-12

Arbusto a arvoreta de até 5 metros de altura, ramos novos, face abaxial das folhas, face adaxial das folhas novas, inflorescências, flores e frutos amareladopardacentos, vilosos; ramos mais velhos cilíndricos, acinzentados, de pubescentes a glabrescentes; tronco com casca externa áspera, acinzentada e liquenizada. Folhas de obovadas a elípticas, ápice de obtuso a arredondado, às vezes retuso, base cuneada, bordo revoluto, coriáceas, discolores, 45-100×25-50 mm; nervura principal sulcada na face adaxial e saliente na abaxial; nervuras secundárias de 7-12 pares; nervura marginal não bem definida por apresentar os laços de fechamento das nervuras secundárias em ângulo próximo a reto, 2-3 $\mathrm{mm}$ do bordo; nervura intramarginal ca. $1 \mathrm{~mm}$ do bordo; pecíolo com 4-6 mm compr. Inflorescências em tirsóides piramidais, com 2 ou 4 (6) axilares terminais ou axilares em nós folhosos, 70-125 mm compr., hipopódio 40-60 mm compr.; 3-5 pares de ramificações laterais, opostas, ascendentes; ferofilos ovados, ca. $4 \mathrm{~mm}$ compr., ocráceopardacentos tomentosos, decíduos; profilos ovados, ca. $2 \mathrm{~mm}$ compr., ocráceo-pardacentos tomentosos, decíduos. Botões florais obcônicos, com 3-4 mm compr., globo petalífero aparente; cálice com 5 lobos triangulares de ápice agudo, pilosos externa e internamente; estames com anteras de deiscência rimosa sigmóides colaterais, muito abertas lateralmente com o interior da teca visível; ovário trilocular. Fruto 


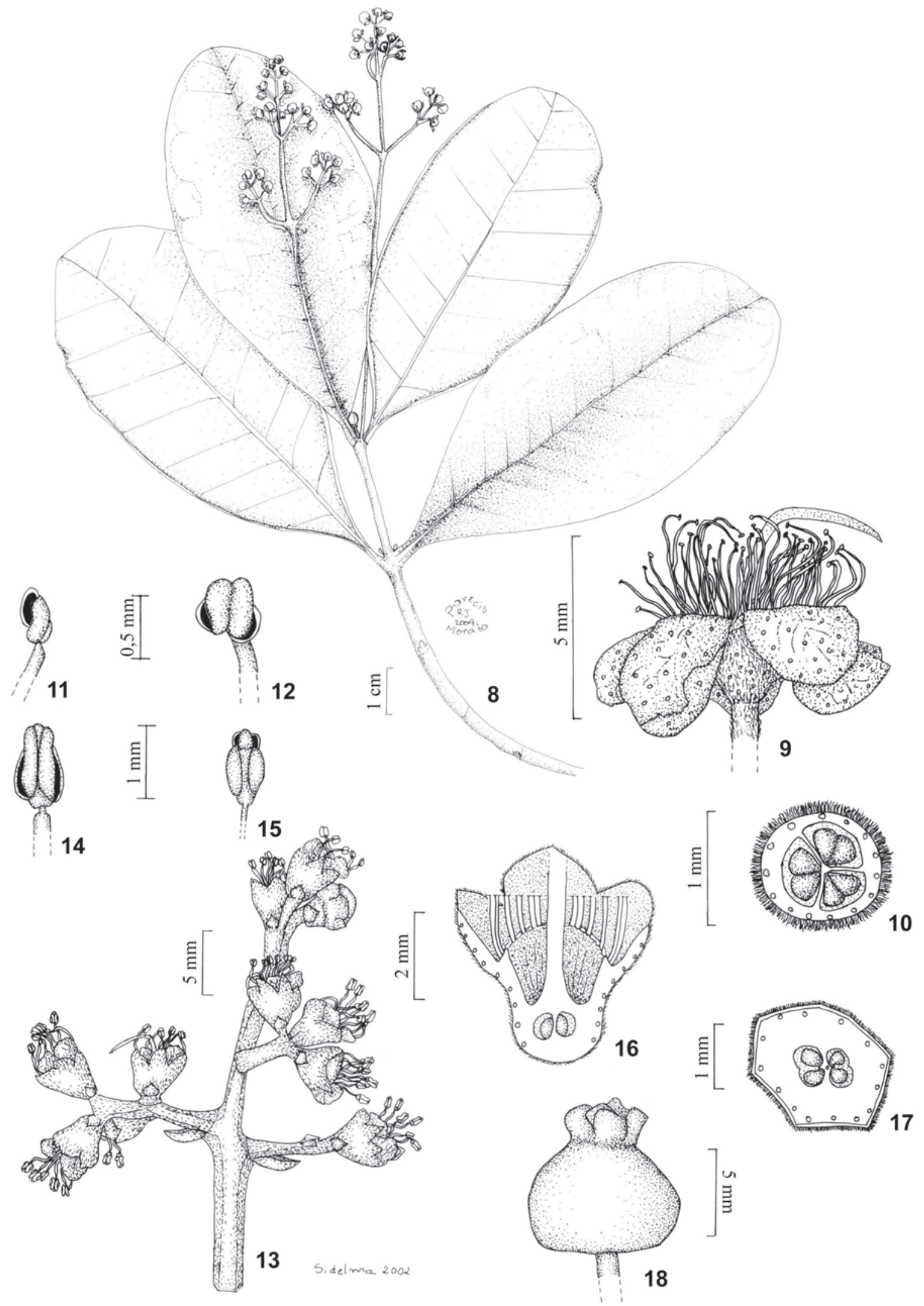

Figuras 8-12. Gomidesia fenzliana O. Berg: 8. Hábito (Souza 218). 9. Flor após antese. 10. Corte transversal do ovário. 11. Antera vista lateral. 12. Antera vista frontal (Souza 171). Figuras 13-18 Gomidesia martiana O. Berg: 13. Inflorescência. 14. Antera vista frontal. 15. Antera vista dorsal. 16. Corte longitudinal da flor aberta. 17. Corte transversal do ovário (Souza 153). 18. Fruto (Menezes 562). 
bacáceo globoso, 10-15 mm diâm., de vermelho a negro quando maduro, com cálice persistente.

Distribuição geográfica: distribui-se pela região litorânea de todo o Brasil a partir de Santa Catarina, transpondo o limite norte do Brasil chegando até a Venezuela (Legrand \& Klein 1967). Nas restingas do Rio de Janeiro ocorre nas seguintes áreas: Reserva da Praia do Sul, Restinga da Marambaia, Jacarepaguá, Maricá, Cabo Frio, Barra de São João e Macaé. Na Restinga da Marambaia foi encontrada na formação arbustiva fechada de cordão arenoso e floresta de cordão arenoso.

Floração: de novembro a março. Frutificação: de fevereiro a maio.

Comentário: a espécie se caracteriza em fase vegetativa por ser a única do grupo que apresenta a folha com o ápice de obtuso a arredondado ou, mais raramente, retuso.

Nomes comuns: guamirim, papaguela.

Material examinado: BRASIL. Rio de Janeiro: Macaé, restinga aberta, 5/V/1981, fr., Araujo 4420 (GUA). Mangaratiba, Restinga da Marambaia, Praia da Armação, 22/XI/1999, vg., Menezes 683 (RBR); 20/I/2001, fl., Souza 171 (RBR); Ilha da Marambaia, Praia Grande, 18/XII/2002, fl., Souza 218 (RBR). Rio de Janeiro, Restinga da Marambaia, 9/I/1999, vg., Souza 51 (RBR); 15/I/1999, vg., Souza 64 (RBR).

2.2. Gomidesia martiana O. Berg, Fl. bras. 14(1): 12. 1857.

Tipo: Habitat in prov. Rio de Janeiro: Sellow 147 (foto do isosintipo P!).

Fig. 13-18

Arbusto a arvoreta de até 6 metros de altura, ramos novos, face abaxial das folhas, pecíolos, inflorescências, flores e frutos com indumento amarelo-farináceo; ramos mais velhos semi-cilíndricos, castanho-claro, glabro; tronco com casca externa áspera, liquenizado. Folhas lanceoladas ou oblongas, ápice acuminado, base aguda, bordo não revoluto, coriáceas, discolores, 125-220 $\times 35-50 \mathrm{~mm}$; nervura principal sulcada na face adaxial e saliente na abaxial; nervuras secundárias de 17-22 pares; nervura marginal 2-3 $\mathrm{mm}$ do bordo; nervura intramarginal ca. $0,5 \mathrm{~mm}$ do bordo; pecíolo com $5 \mathrm{~mm}$ compr. Inflorescências em tirsóides piramidais, 2-4, axilares terminais ou axilares em nós folhosos, 75-100 mm compr., hipopódio 30-60 mm compr., ramos compressos e costados; 3-4 pares de ramificações laterais, opostas, patentes a ascendentes, terminadas em tríades; ferofilos lanceolados, 3-7 mm compr., com indumento amarelo-farináceo na face abaxial e amarelo-tomentoso na face adaxial, decíduos; profilos ovados ca. $2 \mathrm{~mm}$ compr., ocráceo-pardacentos tomentosos. Botões florais obcônicos, com $4 \mathrm{~mm}$ compr., globo petalífero aparente; cálice com 5 lobos triangulares de ápice obtuso, amarelo-farináceo externamente e amarelo-tomentoso internamente; estames com anteras de deiscência rimosa sigmóide oblongas, sacos polínicos dispostos em alturas levemente diferentes; ovário 5-costado, bilocular. Fruto bacáceo globoso ou ovado, $10 \mathrm{~mm}$ diâm., amarelado quando maduro, cálice persistente.

Distribuição geográfica: Sul da Bahia, Espírito Santo e Rio de Janeiro. Nas Restingas do Rio de Janeiro ocorre nas seguintes áreas: Restinga da Marambaia, Jacarepaguá, Maricá, Cabo Frio, Barra de São João e Macaé. Na Restinga da Marambaia foi encontrada na formação arbustiva aberta não inundável, arbustiva fechada de cordão arenoso, floresta inundável e floresta de cordão arenoso.

Floração: de novembro a fevereiro. Frutificação: de fevereiro a junho.

Comentário: a espécie apresenta um indumento característico na face abaxial das folhas, partes jovens dos ramos, inflorescências, flores e frutos, denominado na obra princeps como farináceo e de coloração amarelada.

Material examinado: BRASIL. Rio de Janeiro: Mangaratiba, Restinga da Marambaia, Pombeba, 4/II/1997, fl., Araujo 10543 (GUA); área da Aeronáutica, 3/V/1998, fl., Menezes 643 (RBR); 3/I/2002, fl., Menezes 889 (RBR); Praia da Armação, 28/XII/1998, fl., Menezes s.n. (RBR); 16/II/2000, fl., Menezes 646 (RBR); Praia da Gaeta, 12/VI/2000, fr., Menezes 562 (RBR). Rio de Janeiro, Restinga da Marambaia, 23/XII/2000, fl., Souza 153 (RBR).

3. Marlierea Cambess., Fl. Bras. Mer. 2: 373. 1833. Lectótipo: $M$. suaveolens Cambess., designado por McVaugh (1956).

O gênero é exclusivamente americano com cerca de 95 espécies na América do Sul, das quais a maioria é encontrada no sul, sudeste e centroeste do Brasil (Barroso \& Peixoto 1995).

3.1. Marlierea tomentosa Cambess., Fl. Bras. Merid. 2:373. 1833.

Tipo: In sylvis prope portum Guaratuba, urbem extremam provinciae $S$. Pauli, proximam provinciae S. Catharinae. St. Hilaire s.n. (foto do tipo "voyage d'August de Saint-Hilaire, de 1816 à 1821" P!)

Fig. 19-24 


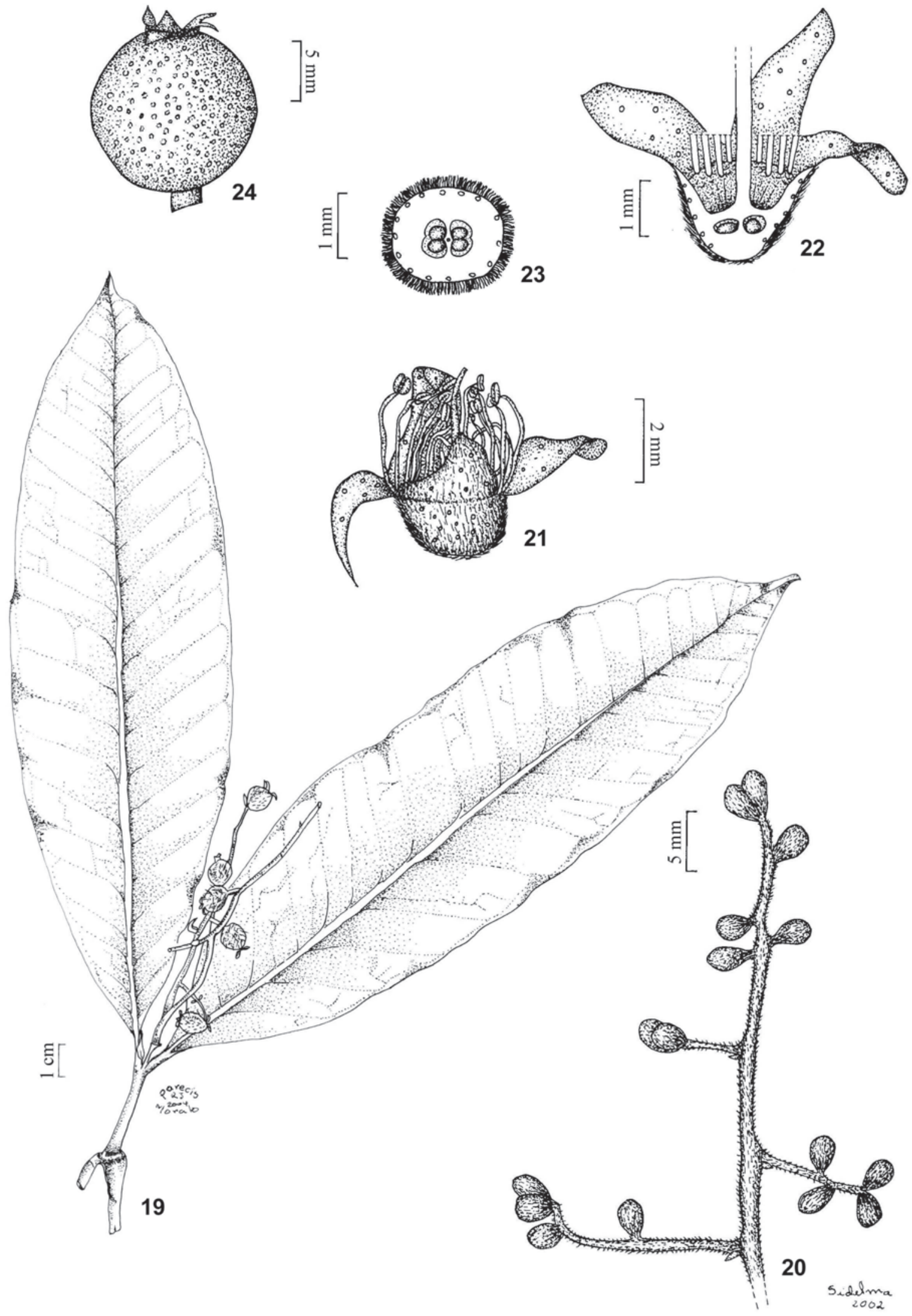

Figuras 19-24. Marlierea tomentosa Cambess: 19. Hábito (Souza 313). 20. Inflorescência. 21. Flor após antese. 22. Corte longitudinal da flor. 23. Corte transversal do ovário (Silva Neto 48). 24. Fruto (Menezes 610). 
Arvoreta a árvore de até 7 metros de altura, ramos novos, pecíolos novos, face abaxial das folhas novas, inflorescências, flores e frutos albo-tomentosos; ramos e folhas velhas pubescentes a glabrescentes; tronco com casca externa áspera e desprendendo-se em placas. Folhas elíptica-oblongas, ápice acuminado, base obtusa a arredondada, bordo não revoluto, coriáceas, discolores, pontuações escurecidas evidentes em ambas as faces, 150-320(360)×60-115(150) mm; nervura principal sulcada na face adaxial e saliente na abaxial; nervuras secundárias 15-18 pares, visíveis em ambas as faces; nervura marginal 3-10 mm do bordo, primeira nervura intramarginal $1-5 \mathrm{~mm}$ do bordo e a segunda nervura intramarginal ca. 0,5-1 $\mathrm{mm}$ do bordo; pecíolo com 10-15 mm compr., enegrecido depois de herborizado. Inflorescências em panículas, 2-4 axilares terminais, 70-200 mm compr., hipopódio de 10-40 mm compr.; 5-7 pares pares de ramificações laterais, alternas, ramificadas; ferofilos oblongos na base da inflorescência com 20-30×5-10 mm, envolvendo a inflorescência nova, e ovados na base dos ramos da inflorescência com ca. $1 \mathrm{~mm}$ compr., decíduos; profilos decíduos, não vistos. Botões florais obovados, ca. $4 \mathrm{~mm}$ compr.; botão floral com cálice fechado, abrindo-se em 4-5 lobos, irregulares, profundamente fendidos, externamente albo-tomentoso e glabro internamente; pétalas ausentes; hipanto desenvolvido sobre o ápice do ovário; ovário bilocular. Fruto bacáceo globoso, 10-15 mm diâm., negro quando maduro, com lobos do cálice persistentes; sementes 1-2 por fruto.

Distribuição geográfica: do Rio de Janeiro a Santa Catarina (Legrand \& Klein 1971a). Nas Restingas do Rio de Janeiro ocorre nas seguintes áreas: Reserva da Praia do Sul, Restinga da Marambaia e São João da Barra. Na Restinga da Marambaia foi encontrada na floresta inundável e floresta de cordão arenoso.

Floração: de fevereiro a junho. Frutificação: de maio a agosto.

Comentário: a espécie, entre as Myrtaceae da Restinga da Marambaia, é bastante característica por apresentar folhas com maior dimensão em comprimento, ultrapassando $150 \mathrm{~mm}$. Sua ocorrência é muito rara, sendo apenas encontrada, em pequenas populações, nos locais cujo solo é periodicamente encharcado.

Nomes vulgares: guapurana, guapurunga.

Material examinado: BRASIL. Rio de Janeiro: Mangaratiba, Restinga da Marambaia, Gaeta, 17/V/2000, fl. fr., Menezes 610 (RBR); 28/VI/2003, fl., Souza 257 (RBR); 2/V/2004, fr., Souza 313 (RBR). Nova Iguaçu, Reserva Biológica do Tinguá,
8/VII/1993, fr., Rosa 415 (RBR); 23/IV/1994, fl., Silva Neto 48 (RBR). Paraty, Fazenda Laranjeiras, 10/VI/1976, fl., Martinelli 963 (RB); 5/VII/1989, fr., Farney 2308 (RB); APA do Cairuçu, 16/II/1993, fl., A. Filho 117 (RB); 24/VIII/1995, fr., Castellar 27 (RB); 1/VII/1993, fr., Marquete 1155 (RB); 3/VIII/1994, fr., Moura 19 (RB); Trindade, 29/VI/1995, fr., Campos 56 (RB).

4. Myrcia DC. ex Guill., Dict. Class. Hist. Nat. 11: 401.1827.

Lectótipo: M. bracteolaris (Poir.) DC., designado por McVaugh (1956).

O gênero distribui-se desde o México e Caribe até o norte da Argentina, sendo que o maior número de espécies ocorre nas regiões centro-oeste e sudeste do Brasil (Landrum \& Kawasaki, 1997). Após o trabalho de Berg $(1857 ; 1858 ; 1859)$, nenhuma revisão do gênero foi feita e o número de espécies vem sendo estimado em torno de 300 (McVaugh 1969). Na Restinga da Marambaia está representado por cinco espécies: M. acuminatissima, M. lundiana, M. multiflora, $M$. recurvata e $M$. richardiana.

4.1. Myrcia acuminatissima O. Berg, Fl. bras., 14(1): 167. 1857.

Tipo: Habitat ad urbem Santos in prov. S. Pauli: Sellow (foto do isotipo K!)

Aulomyrcia racemosa O. Berg, Fl. bras., 14(1): 88. 1857.

Aulomyrcia gaudichaudiana O. Berg, Fl. bras., 14(1): 88. 1857.

Myrcia racemosa (O. Berg) Kiaersk., Enum. Myrt. bras., 72. 1893.

Fig. 25-28

Arbusto a árvore de até 8 metros de altura; ramos jovens, pecíolos, inflorescências, flores e frutos jovens canescentes e vilosos, folhas com indumento canescente pubescente, sendo glabrescente na face adaxial; tronco com casca externa laminada desfolhando em lâminas papiráceas, acinzentada, liquenizada, com manchas verdes. Folhas elípticaoblongas ou lanceoladas, ápice longamente acuminado, base obtusa, bordo levemente revoluto, cartáceas, com pontuações evidentes em ambas as faces, 40-75 $\times 10-30 \mathrm{~mm}$; nervura principal sulcada na face adaxial e saliente na abaxial; nervuras secundárias de 9-12 pares, visíveis em ambas as faces; nervura marginal 1-2 $\mathrm{mm}$ do bordo; nervura intramarginal ca. 0,5 $\mathrm{mm}$ do bordo; pecíolo 4-5 $\mathrm{mm}$ compr. Inflorescências em panículas, 4-6 axilares terminais e 
axilares em nós folhosos, 40-60 mm compr., hipopódio de 5-10 mm compr.; 2-4 pares de ramificações laterais alternas, podendo o primeiro ser oposto; ferofilos ovados ou lanceolados, 1-3 mm compr., decíduos; profilos lanceolados, $2 \mathrm{~mm}$ compr., decíduos. Botões florais obovados, com $2 \mathrm{~mm}$ compr., globo petalífero pouco aparente no ápice do botão; cálice com 5 lobos triangulares de ápice agudo, proeminentes, iguais; hipanto prolongado ca. $0,5 \mathrm{~mm}$ sobre o ápice do ovário, internamente glabro; ovário bilocular. Fruto bacáceo globoso, 6 mm diâm., vermelho e glabrescente quando maduro, coroado pelo hipanto, com lobos do cálice persistentes.

Distribuição geográfica: do sul da Bahia ao norte de Santa Catarina, preferencialmente nas planícies costeiras e muito raramente nas matas de encosta, atingindo as Serras de Minas Gerais (Legrand \& Klein 1969). Nas Restingas do Rio de Janeiro ocorre nas seguintes áreas: Reserva da Praia do Sul, Restinga da Marambaia, Jacarepaguá, Cabo Frio e Macaé. Na Restinga da Marambaia foi encontrada na floresta inundável e floresta de cordão arenoso.

Épocas de floração de outubro a janeiro; frutificação de janeiro a julho.

Comentário: M. acuminatissima foi incluída como sinônimo de M. racemosa por Legrand \& Klein (1969), entretanto não foi considerado o princípio da prioridade de publicação de $M$. acuminatissima, a qual é restabelecida no presente trabalho. A espécie foi encontrada com muita freqüência nas formações florestais com solo encharcado. Os tricomas canescentes nos ramos, folhas, flores e frutos e a folha com ápice longo acuminado são caracteres importantes no reconhecimento da espécie.

Material examinado: BRASIL. Rio de Janeiro: Mangaratiba, Restinga da Marambaia, 3/VI/1972, fr., Sucre 9171 (RB); Praia da Armação, 23/XII/1998, fl., Menezes 395 (RBR); 4/I/1999, fl., Menezes 216 (RBR); 29/V/1999, fr., Menezes 267 (RBR); 19/III/2000, fr., Menezes s.n. (RBR); 8/IV/2000, fr., Menezes s.n. (RBR); 3/I/2002, fl., Menezes 879 (RBR).

4.2. Myrcia lundiana Kiaersk., Enum. Myrt. bras., 78. 1893.

Aulomyrcia vauthieriana O. Berg, Linnaea 30: 655. 1861.

Tipo: Brasilia, Vauthier (foto do tipo P!).

Fig. 29

Arbusto a arvoreta de até 6 metros de altura; glabra, com apenas os ramos jovens e inflorescências avermelhado-pubescentes; tronco com casca externa laminada desfoliante em placas rígidas, deixando um aspecto liso, avermelhado. Folhas ovadas ou elípticas, ápice acuminado, base aguda, bordo um pouco revoluto, coriáceas, discolores, com a face adaxial brilhante, densamente pontuadas, 30-80 $\times 15-40 \mathrm{~mm}$; nervura principal sulcada na face adaxial e saliente na abaxial; nervuras secundárias de 8-12 pares, visíveis em ambas as faces; nervura marginal 0,5-2 $\mathrm{mm}$ do bordo; nervura intramarginal ca. 0,1-0,5 mm do bordo; pecíolo $3 \mathrm{~mm}$ compr., amarelado na natureza e escurecendo após herborizado. Inflorescências em panículas, 2-6 axilares terminais e axilares em nós folhosos, 30-80 $\mathrm{mm}$ compr., hipopódio até $30 \mathrm{~mm}$ compr.; 3-4 pares de ramificações laterais alternas, podendo o primeiro ser oposto; ferofilos ovados ou lanceolados, 2-4 $\mathrm{mm}$ compr., decíduos; profilos ovados, 1-2 mm compr., decíduos. Botões florais obovados, pubérulos no ápice, com $2 \mathrm{~mm}$ compr., globo petalífero pouco aparente no ápice do botão; cálice com 5 lobos arredondados, proeminentes, desiguais com 2 maiores e 3 menores; hipanto prolongado ca. $0,5 \mathrm{~mm}$ sobre o ápice do ovário; ovário bilocular. Fruto bacáceo globoso, 5-8 mm diâm., negro quando maduro, coroado pelo hipanto, com lobos do cálice persistentes.

Distribuição geográfica: restrita as restingas do Rio de Janeiro, ocorrendo nas seguintes áreas: Restinga da Marambaia, Jacarepaguá, Marica, Cabo Frio e Macaé. Na Restinga da Marambaia foi encontrada na formação arbustiva aberta não inundável, arbustiva fechada de cordão arenoso, arbustiva fechada de póspraia e floresta de cordão arenoso.

Épocas de floração de dezembro a junho; frutificação de abril a setembro.

Comentário: os botões florais apresentam um apêndice, semelhante a um profilo, localizado na porção mediana do hipanto. Tal estrutura não foi observada com freqüência em outras espécies e estudos anatômicos deverão ser realizados para investigar a origem do referido apêndice.

Material examinado: BRASIL. Rio de Janeiro: Mangaratiba, Restinga da Marambaia, Praia da Armação, 23/XII/1998, fl., Menezes 392 (RBR); 29/V/1999, fl., Menezes 295 (RBR). Rio de Janeiro, Restinga da Marambaia, 3/V/1998, fl., Souza 20 (RBR); 3/V/1998, fl., Souza 21 (RBR); 27/VI/1999, fl., Menezes 633 (RBR); 27/VI/1999, fr., Souza s.n. (RBR); 9/XI/1999, fr., Souza 133 (RBR); 8/VI/2000 fl., Silva s.n. (RBR); 9/VI/2001, fl., Souza 204 (RBR); 9/VI/2001, fl., Souza 207 (RBR). 
4.3. Myrcia multiflora (Lam.) DC., Prodr. 3: 244. 1828.

Eugenia multiflora Lam., Encycl., Botanique 3: 302. 1789.

Tipo: Cayenne, Stoupy (foto do tipo P!).

Fig. 30-31

Arbusto a árvore de até 18 metros de altura; planta glabra, com apenas os ramos jovens e inflorescências pubérulos ou pubescentes; tronco com casca externa laminada desfoliante em pequenas lâminas finas, com coloração esbranquiçada e rosada. Folhas elíptica ou obovada, ápice acuminado ou obtuso-acuminado, base cuneada, bordo um pouco revoluto, cartáceas, discolores, densamente pontuadas, $25-50 \times 10-25 \mathrm{~mm}$; nervura principal sulcada na face adaxial e saliente na abaxial; nervuras secundárias de 12-17 pares, visíveis em ambas as faces; nervura marginal $0,5-1,5 \mathrm{~mm}$ do bordo; nervura intramarginal ca. $0,1 \mathrm{~mm}$ do bordo, quase inconspícua; pecíolo 2-5 $\mathrm{mm}$ de compr., enegrecido após herborizado. Inflorescências em panículas, 2-4 ramifloras na axila ou não de ferofilos, 25-70 mm compr., hipopódio de 15-30 mm compr.; 2-4 pares de ramificações laterais alternas, podendo o primeiro ser oposto; ferofilos na base da inflorescência lanceolados, $5 \mathrm{~mm}$ compr., decíduos; profilos ca. $1 \mathrm{~mm}$ compr., decíduos. Botões florais globosos, com $2 \mathrm{~mm}$ compr., globo petalífero aparente, ca. da metade do tamanho do botão; cálice com 5 lobos semi-circulares, pouco salientes, iguais; hipanto prolongado ca. $0,5 \mathrm{~mm}$ sobre o ápice do ovário; ovário bilocular. Fruto bacáceo globoso, $5 \mathrm{~mm}$ diâm., negro quando maduro, coroado pelo hipanto, com lobos do cálice persistentes.

Distribuição geográfica: do norte da América do Sul até o Rio Grande do Sul (Legrand \& Klein 1969). Nas Restingas do Rio de Janeiro ocorre nas seguintes áreas: Reserva da Praia do Sul, Restinga da Marambaia, Jacarepaguá, Cabo Frio e Macaé. Na Restinga da Marambaia foi encontrada na formação arbustiva aberta não inundável, floresta inundável e floresta de cordão arenoso.

Épocas de floração de julho a fevereiro e frutificação de outubro a abril.

Comentário: a espécie apresenta uma ampla distribuição geográfica, ocorrendo em diversas fitofisionomias e apresentando uma grande variação morfológica, principalmente foliar, o que acarretou uma grande quantidade de sinônimos, como já mencionado por Legrand \& Klein (1969). A exemplo do que já mencionado em $M$. lundiana observou-se, nos botões florais, a presença de um apêndice em forma de profilo, localizado na porção mediana do hipanto
Material examinado: BRASIL. Rio de Janeiro: Mangaratiba, Restinga da Marambaia, Praia da Armação, 22/XII/1998, fl., Menezes s.n. (RBR); 23/XII/1998, fr., Menezes s.n. (RBR); 16/II/2000, fl., Menezes s.n. (RBR); 8/IV/2000, fr., Menezes 672 (RBR); 20/I/2001, fl., Souza 169 (RBR).

4.4. Myrcia recurvata O. Berg, Fl. bras. 14(1): 166. 1857.

Tipo: Habitat in prov. Espírito Santo et Rio de Janeiro: Sellow (foto do isosintipo, K!), Pohl n. 5865; Raben n. 735.

Fig. 32-34

Arbusto a arvoreta de até 6 metros de altura; com os ramos novos, inflorescências e flores ocráceopubescentes, face abaxial das folhas glabrescente; tronco com casca externa suberosa e fissurada. Folhas ovadas ou lanceoladas, ápice longamente acuminado, base obtusa a arredondada, bordo pouco revoluto, coriáceas, com face adaxial brilhante, pontuações translúcidas esparsas, 50-150×20-70 mm; nervura principal sulcada na face adaxial e saliente na abaxial; nervuras secundárias de 10-12 pares, visíveis em ambas as faces e muito salientes na abaxial; nervura marginal 2-4 $\mathrm{mm}$ do bordo; nervura intramarginal ca. 0,5-1 mm do bordo; pecíolo 6-10 mm compr. Inflorescências em tirsóides, 2-4 axilares terminais ou axilares em nós folhosos, 50-100 mm compr., hipopódio 25-40 mm compr.; 4-5 pares de ramificações laterais, o primeiro par sempre oposto e os outros opostos ou subopostos; ferofilos não vistos, decíduos; profilos ovados, $1 \mathrm{~mm}$ compr., decíduos. Botões florais obovados, com $3 \mathrm{~mm}$ compr., globo petalífero aparente no botão; cálice com 5 lobos deltóides, iguais; hipanto não prolongado sobre o ápice do ovário; ovário bilocular. Fruto bacáceo globoso ou elipsóide, $10 \mathrm{~mm}$ diâm., negro quando maduro, com lobos do cálice persistentes.

Distribuição geográfica: distribui-se pelas Restingas do Espírito Santo e Rio de Janeiro; ocorre nas seguintes áreas do Rio de Janeiro: Reserva da Praia do Sul, Restinga da Marambaia, Jacarepaguá, Cabo Frio e Macaé. Na Restinga da Marambaia foi encontrada na formação arbustiva aberta não inundável, arbustiva fechada de cordão arenoso e floresta de cordão arenoso.

Épocas de floração de setembro a dezembro e frutificação de outubro a janeiro.

Comentário: espécie muito característica pelo seu tronco com a casca externa suberosa e fissurada, além das folhas, após herborizadas, dobradas na área da nervura principal e, geralmente, ocultando a face 
adaxial. $M$. recurvata é uma espécie bastante afim de M.ovata, registrada até o momento apenas para as restingas de Cabo Frio. Estudos futuros serão necessários em relação ao posicionamento de ambos os táxons como espécies distintas.

Material examinado: BRASIL. Rio de Janeiro: Mangaratiba, Restinga da Marambaia, Praia da Armação, 22/XII/1998, fr., Menezes 234 (RBR); 23/XII/1998, fl., Menezes 394 (RBR); 28/XII/1998, fr., Menezes 393 (RBR); 24/X/1999, fl., Menezes 506 (RBR); 11/XI/2000, fl., Menezes 709 (RBR); 20/I/2001, fr., Souza 167 (RBR). Rio de Janeiro, Restinga da Marambaia, 20/X/1999, fl., Menezes 570 (RBR); 27/XI/1999, fr., Silva 4 (RBR); 20/X/2000, fl., Melo 5 (RBR); 29/XII/2000, fr., Souza 160 (RBR).

4.5. Myrcia richardiana (O. Berg) Kiaersk., Enum. Myrt. bras.: 97. 1893.

Aulomyrcia richardiana O. Berg, Linnaea 30: 664. 1861. Tipo: Habitat in silvis montium Serra dos Orgaos prope Rio de Janeiro (Vauthier) (foto do tipo P!).

Aulomyrcia lucida O.Berg, Fl. bras. 14(1): 118. 1857. (Tipo: Habitat in prov. Rio de Janeiro: ad urbem: Gaudichaud; ad montem Serra de Tinguá: Schott n. 1027 (foto do isosintipo K!). Syn. nov.

Myrcia dilucida G.M.Barroso, Bradea 5(35): 358. 1990. (Tipo: Schott 1027). Nom. nov.

Myrcia grandiglandulosa Kiaersk., Enum. Myrt. bras.: 83. 1893. (Tipo: Brasil, Rio de Janeiro, Santo Ângelo; Glaziou 13879 (isotipo R!). Syn. nov.

Fig. 35

Arbusto a árvore de 18 metros de altura; com ramos novos, folhas novas, inflorescências e flores castanho a ferrugíneo pubescentes; tronco com casca externa áspera desprendendo-se em placas. Folhas elípticas, ovadas, ou oblongas, ápice acuminado; base cuneada, bordo revoluto, coriáceas, discolores, com pontuações translúcidas grandes e evidentes em ambas as faces, 30-110 $\times 15-50 \mathrm{~mm}$; nervura principal um pouco saliente na face adaxial e fortemente saliente na face abaxial, com maior concentração de tricomas em relação ao restante da lâmina foliar; nervuras secundárias 10-20 pares, salientes em ambas as faces; nervura marginal a $2 \mathrm{~mm}$ do bordo; nervura intramarginal a ca. $0,5 \mathrm{~mm}$ do bordo; pecíolo $3-8 \mathrm{~mm}$ compr. Inflorescências em tirsóides, 2-4 axilares terminais ou axilares em nós folhosos, 50-100 mm compr., hipopódio 20-60 mm compr.; 3-4 pares de ramificações laterais opostas; ferofilos lanceolados, 2-10 mm compr., decíduos; profilos ovados, $1 \mathrm{~mm}$ compr., decíduos. Botões florais obovados, 2-4 mm compr., globo petalífero aparente no botão; cálice com 5 lobos triangulares ou arredondados, iguais; hipanto prolongado ca. $0,5 \mathrm{~mm}$ sobre o ápice do ovário; ovário trilocular. Fruto bacáceo globoso, $10 \mathrm{~mm}$ diâm., vermelho a negro quando maduro, coroados pelo hipanto, com lobos do cálice persistentes.

Distribuição geográfica: distribui-se do Espírito Santo ao Rio Grande do Sul (Legrand \& Klein 1969). Nas restingas do Rio de Janeiro só foi encontrada na Restinga da Marambaia ocorrendo na floresta inundável.

Épocas de floração de setembro a dezembro e frutificação de janeiro a fevereiro.

Comentário: Kiaerskou (1893), na obra que trata das Myrtaceae brasileiras, subordinou M. richardiana e M. grandiglandulosa em grupos distintos do subgênero Aulomyrcia. Nas descrições das espécies foram observadas várias sobreposições de caracteres morfológicos que foram utilizados como diagnósticos por Kiaerskou (1893). O exame do tipo de M. grandiglandulosa e da foto do tipo de $M$. richardiana, juntamente com a avaliação das coleções dos herbários RB, R, GUA, mostraram que M. grandiglandulosa é um novo sinônimo.

Berg (1857) descreve A. lucida considerando as variedades $\alpha$-parvifolia (Gaudichaud s.n.) e $\beta$-grandifolia (Schott 1027), ambas coletadas no Rio de Janeiro. A análise da diagnose das duas variedades, o exame de coleções de herbário e a consulta da foto do isosintipo do material Schott 1027 permitiu concluir a ausência de caracteres diagnósticos que sustentem a validade dos táxons infra-específicos. Barroso (1990) propôs $M$. dilucida como um novo nome para A. lucida, abrangendo as duas variedades acima mencionadas. Essa proposta deve-se à existência prévia de Myrcia lucida McVaugh (1969), o que implicaria em um homônimo posterior caso fosse feita uma nova combinação. Analisando a descrição, a foto do isosintipo de A. lucida, Schott 1027, e o estudo das coleções verificou-se a ausência de caracteres distintos entre $A$. lucida e $M$. richardiana.

M. richardiana é uma espécie com ampla variação morfológica, principalmente, em relação as dimensões das folhas e inflorescências. Sustenta-se como epíteto válido $M$. richardiana, apesar da existência do epíteto mais antigo, A. lucida, uma vez que a nova combinação para o gênero Myrcia, implicaria em um nome ilegítimo devido à existência prévia de Myrcia lucida McVaugh (1969).

A espécie apresenta folhas muito características, com pontuações translúcidas grandes e muito evidentes 


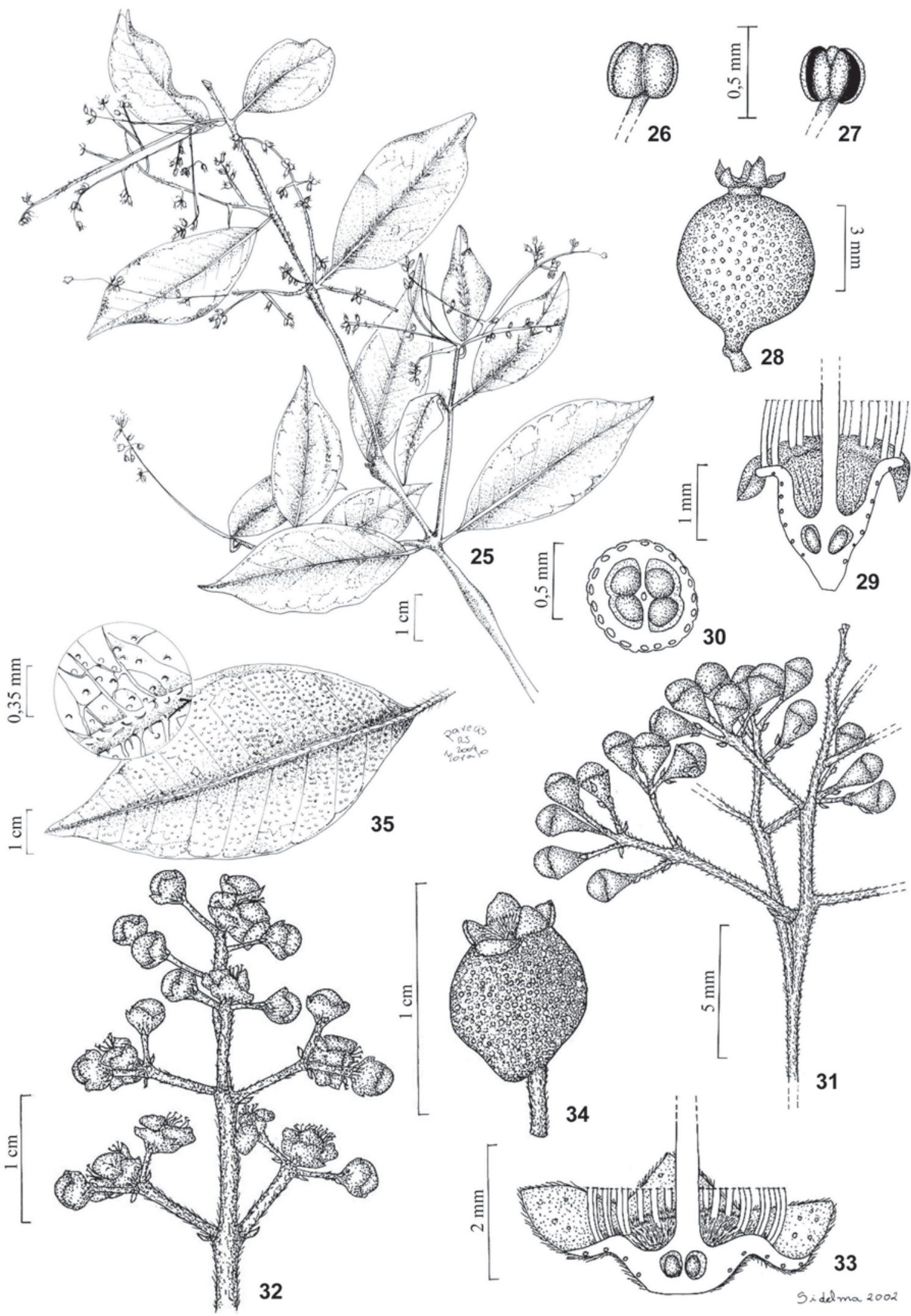

Figuras 25-28. Myrcia acuminatissima O.Berg: 25. Hábito. 26. Antera fechada. 27. Antera aberta (Menezes 395). 28. Fruto (Menezes 288). Figura 29. Myrcia lundiana Kiaersk.: corte longitudinal da flor (Souza 207). Figuras 30-31. Myrcia multiflora (Lam.) DC.: 30. Corte transversal do ovário. 31. Inflorescência (Souza 169). Figuras 32-34. Myrcia recurvata O. Berg: 32. Inflorescência. 33. Corte longitudinal da flor (Menezes 709). 34. Fruto (Souza 160). Figura 35. Myrcia richardiana (O. Berg) Kiaersk.: folha (Souza 314). 
em ambas as faces, além de uma nervação reticulada, saliente e evidente em ambas as faces. A distribuição de $M$. richardiana nas restingas do Rio de Janeiro demonstrou que é rara nas restingas, ressaltando-se que na área de estudo foram localizados poucos indivíduos.

Material examinado: BRASIL. Espírito Santo: Santa Tereza, Estação Biológica de Santa Lúcia, 24/XI/1988, fl., Fernandes 2648 (RB). Rio de Janeiro: Mangaratiba, Restinga da Marambaia, próximo à lagoa Vermelha, 17/II/2004, vg., Souza 314 (RBR). Niterói, Pico do Alto Moirão, 14/I/1982, fr., Andreata 388 (RB). Paraty, Ilha da Cotia, 22/XI/1989, fl., Marques 187 (RB). Petrópolis, Carangola, X/1943, fl., Góes e Constantino 604 (RB); Ibid., 28/I/1968, fl., Sucre 2251 (RB). Rio de Janeiro, Morro do Leme, XI/1966, fl., Sucre 1202 (RB); 27/X/1941, fl., Kuhlmann s.n. (RB); Copacabana, APA Chacrinha, 8/XII/2003, fl., Cardoso 41 (RB); Mesa do Imperador, 10/XI/1947, fl., Duarte 992 (RB); Corcovado, 24/XI/1971, fl., Sucre 7968 (RB); Pico da Tijuca, 3/II/1971, fr., Sucre 7381 (RB); Morro do Pão de Açúcar, 17/X/1978, fl., Lima 717 (RB); Pedra da Gávea, 7/II/1971, fl., Sucre 7417 (RB). Teresópolis, PARNA Serra dos Órgãos, 6/IX/1998, fl., Pardo 55 (RB).

\section{Agradecimentos}

À Dra Graziela M. Barroso (in memoriam), pelos valiosos ensinamentos; ao Marcos Sobral, pelas sugestões; ao Campo de Provas da Marambaia (Exército) e Centro de Adestramento da Ilha da Marambaia (Marinha) por possibilitar o desenvolvimento deste estudo no local e pelo apoio fornecido; à FAPERJ, pela bolsa de Mestrado concedida ao primeiro autor; à Fundação O Boticáio de Proteção à Natureza, pelo apoio fornecido ao Projeto Marambaia; às ilustradoras Sidelma e Parecis Morato, pela dedicação.

\section{Referências bibliográfica}

Araujo, D.S.D. 2000. Análise florística e fitogeográfica das restingas do Estado do Rio de Janeiro. Tese de doutorado, UFRJ.

Assumpção, J. \& Nascimento, M.T. 2000. Estrutura e composição florística de quatro formações vegetais de restinga do complexo lagunar Grussaí/Iquipari, São João da Barra, RJ, Brasil. Acta Botanica Brasilica 14(3): 301-315.
Barroso, G.M. 1990. Myrtaceae - novidades taxonômicas. Bradea 5(35): 357-360.

Barroso, G.M. \& Peixoto, A.L. 1995. Myrtaceae da Reserva Florestal de Linhares, ES, Brasil - gêneros Calyptranthes e Marlierea. Boletim do Museu de Biologia Mello Leitão (N. Ser) 3: 3-38.

Barroso, G.M.; Morim, M.P.; Peixoto, A.L. \& Ichaso, C.L.F. 1999. Frutos e Sementes: Morfologia aplicada à sistemática de dicotiledôneas. Viçosa, Ed. UFV.

Berg, O. 1855. Revisio Myrtacearum Americae. Linnaea 27(1): 1-128.

Berg, O. 1856a. Revisio Myrtacearum Americae. Linnaea 27(2, 3): 129-384.

Berg, O. 1856b. Revisio Myrtacearum Americae. Linnaea 27(4): 385-512.

Berg, O. 1857. Myrtaceae. In: C.P.F. Martius (ed.). Flora Brasiliensis 14(1): 1-468.

Berg, O. 1858. Myrtaceae. In: C.P.F. Martius (ed.). Flora Brasiliensis 14(1): 469-528.

Berg, O. 1859. Myrtaceae. In: C.P.F. Martius (ed.). Flora Brasiliensis 14(1): 529-656.

Briggs, B.G. \& Johnson, L.A.S. 1979. Evolution in the Myrtaceae- Evidence from inflorescence struture. Proceedings of the Linnean Society of New South Wales 102 : 157-256.

Candolle, A.P. 1826. Dict. Classique d'hist. naturelle. v. 11. Paris.

Harrington, H.D. \& Durrel, L.W. 1957. How identify plants. Chicago, The swallow Press, Inc.

Hickey, L.J. 1973. Classification of the architecture of Dicotyledonous leaves. American Journal of Botany 60(1): 17-33.

Holmgren, P.K.; Holmgren, N.H. \& Barnett, L. 1990. Index Herbariorum. 8. ed. New York, New York Botanical Garden.

Kiaerskou, H. 1893. Enumeratio Myrtacearum brasiliensium. In: E. Warming (ed.) Symbolarum ad Floram Brasiliae Centralis Cognoscendam 39: 1-200.

Landrum, L.R. \& Kawasaki, M.L. 1997. The genera of Myrtaceae in Brazil: an illustrated synoptic treatment and identification keys. Brittonia 49(4): 508-536.

Legrand, C.D. \& Klein, R.M. 1967. Myrtáceas: 1. Gomidesia. In: R. Reitz (ed.). Flora Ilustrada Catarinense: 1-44.

Legrand, C.D. \& Klein, R.M. 1969. Myrtáceas: 3. Myrcia. In: R. Reitz (ed.). Flora Ilustrada Catarinense: 217-330.

Legrand, C.D. \& Klein, R.M. 1971a. Myrtáceas: 5. Marlierea. In: R. Reitz (ed.). Flora Ilustrada Catarinense: 455-487.

Legrand, C.D. \& Klein, R.M. 1971b. Myrtáceas: 6. Calyptranthes. In: R. Reitz (ed.). Flora Ilustrada Catarinense: 489-552.

Lucas, E.J.; Belsham, S.R.; Nic Lughadha, E.M.; Orlovich, D.A.; Sakuragui, C.M.; Chase, M.W. \& Wilson, P.G. 2005. Phylogenetic patterns in the fleshy-fruited Myrtaceae preliminary molecular evidence. Plant Systematics and Evolution 251: 35-51.

Marchiori, J.N.C. 1995. Elementos de dendrologia. Santa Maria., Ed. UFSM.

McVaugh, R. 1956. Nomenclatural notes on Myrtaceae and related families. Taxon 5: 133-147. 
McVaugh, R. 1968. The genera of american Myrtaceae - an interim report. Taxon 17: 354-418.

McVaugh, R. 1969. The botany of the Guayana highland Part VIII - Myrtaceae. Memoirs of the New York Botanical Garden 18(2): 55-286.

Menezes, L.F.T. \& Araujo, D.S.D. 2005 Formações vegetais da Restinga da Marambaia. In: L.F.T. Menezes; D.S.D. Araujo \& A.L. Peixoto (eds.). História Natural da Marambaia: 67-120. Seropédica, Edur.

Mori, S.A.; Boom, B.M.; Carvalho, A.M. \& Santos, T.S. 1983. Ecological importance of Myrtaceae in an eastern brazilian wet forest. Biotropica 15(1): 68-70.

Pereira, M.C.A.; Araujo, D.S.D. \& Pereira, O.J. 2001. Estrutura de uma comunidade arbustiva da restinga de Barra de Marica - RJ. Revista Brasileira de Botânica 24(3): 273-281.
Ribeiro, J.E.L.S.; Hopkins, M.J.G.; Vicentini, A.; Sothers, C.A.; Costa, M.A.S.; Brito, J.M.; Souza, M.A.D.; Martins, L.H.P.; Lohmann, L.G.; Assunção, P.A.C.L.; Pereira, E.C.; Silva, C.F.; Mesquita, M.R. \& Procópi, L.C. 1999. Flora da Reserva Ducke: guia de indentificação das plantas vasculares de uma floresta de terra-firme na Amazônia Central. Amazonas, INPADFID.

Vaz, A.M.S.F.; Lima, M.P.M. \& Marquete, R. 1992. Técnicas e manejo de coleções botânicas. In: IBGE. Manual Técnico da vegetação brasileira. Manuais técnicos em Geociências 1: 55-75.

Wilson, P.G.; O’Brien, M.M.; Gadek, P.A. \& Quinn, C.J. 2001. Myrtaceae revisited: a reassessmente of infrafamilial groups. American Journal of Botany 88: 2013-2025. 